\title{
Dancing in Wandering: On the Wandering Consciousness of Ding Ling's Early Female Writing
}

\author{
Wenxu Nie \\ Chinese Department, School of Literature, Huaqiao University, Quanzhou, China \\ Email: 467907592@qq.com
}

How to cite this paper: Nie, W.X. (2019) Dancing in Wandering: On the Wandering Consciousness of Ding Ling's Early Female Writing. Open Access Library Journal, 6: e5861.

https://doi.org/10.4236/oalib.1105861

Received: October 16, 2019

Accepted: November 3, 2019

Published: November 6, 2019

Copyright $\odot 2019$ by author(s) and Open Access Library Inc.

This work is licensed under the Creative Commons Attribution International License (CC BY 4.0).

http://creativecommons.org/licenses/by/4.0/

\section{(c) (i) Open Access}

\begin{abstract}
Ding Ling's early novels, with the basic characteristics of getting rid of the feudal ideological and pursuing gender liberation, highlighted a strong sense of female subjectivity. However, few people find the wandering consciousness of losing their homeland hidden in the female subjectivity. This wandering consciousness is embodied in woman's pursuit of feelings, ideals and freedom, independent selections physical vagrancy and spiritual vagrancy. In Ding Ling's novels, the body writing of female vagrants and the recognition of loneliness make "going away" no longer an empty declaration, but an alternative choice for women to transcend their subjective spirit. The reason is that Ding Ling's own experience and the rejection of women by the times have all contributed to the formation of her wandering consciousness.
\end{abstract}

\section{Subject Areas}

Literature

\section{Keywords}

Early Novels, Wandering Consciousness, Independent Selections, Body Writing

\section{Introduction}

After the fall of the May 4th Movement, Ding Ling was famous for her bold writing of female consciousness and desire psychology, and created a series of rebellious images of "daughters". The early works in Shanghai, such as Ms. ShaFi's Diary, Meng Ke, A Mao Girl and Shanghai in the Spring of 1930, depicted the life predicament and psychological experience of women wandering in the 
new era from the daily life which could not be avoided.

\section{Women's Images in Wandering}

After the May 4th Movement, Chinese women who had been abandoned by history for thousands of years had the power to make their own choices. At that time, most women still lingered in the feudal tradition and the new civilization, and it was difficult to accept this sudden change. Ding Ling, on the other hand, practiced and did not hesitate to choose to dominate her own destiny. A thorough understanding of Ding Ling's works from 1927 to 1930 reveals that almost all the women in her works are like her, in a vagrant state. They go out of their homes with blood and vision for the future, constantly integrate into the world and participate in life, struggle unremittingly with patriarchal dictatorship and society, and answer the question "after Nora left" in a wandering way.

The images of vagrant women in Ding Ling's works can be roughly divided into three categories: one for emotions, one for independence and one for ideals. Vagrancy and destination are a set of corresponding relationships, just like fishermen fishing at sea and returning home to shore, as well as ships sailing and returning to harbor and coast [1]. Although the purpose of these three types of wandering women is different, they all want to abandon the old living environment and find their own home.

Love elevates the human spirit to the level of dialogue with the mind. Love exists in the form of never-failing life in human society [2]. Women in Ding Ling's works regard love as spiritual sustenance and spiritual home, a source of security. In the search for a new life, a new love, the love of "seeking but not getting" or "gaining but not seeking" often makes them feel confused and helpless. In the face of love, they will never compromise and settle down. They will always say goodbye to the past. Compared with distant family relationships, young girls who go out to study and live alone are more eager to get a stable and reliable love, and to create a better life together with a partner who understands and supports each other. Because of this, they reject the arrangement of family and the introduction of friends with fanatical and frank fantasy of love, hoping to find out "then one can understand me clearly, if not understand me, I want those love, what are those considerate things to do?" [3]. But innocent girls are often hard to get what they want. They are still facing the horrible society of male power. They are exposed to cowardly, indecent and masculine men, which leads them to go on the wander road in pursuit of the true and the best love.

Although she knew that Ling Jishi was not her true love, she could not get rid of her longing for Ling jishi for a while. "In loneliness, I missed Ling Jishi again". "When I went to sleep, I despised beauty, but just woke up from a dream, rubbed her sleeping eyes, and missed the vulgar again". This state of entanglement and pain in feelings not only reflects women's infatuation in love, but also reflects the emptiness and uneasiness in vagrant life, longing for spiritual sustenance. 
Meng Ke, who thought he was going to start a love affair with his second cousin, was soon hurt by the man's hypocrisy. When her second cousin was absent for four or five days, Miss Yang exposed her cousin, whom Meng Ke loved and attached to, and was in the hotel with Mrs. Zhang, a prostitute. At this time, Meng Ke felt that she had fallen into the abyss of hell. "She had to start her wandering career". In order to pursue a better love, Sha Fi and Meng Ke both ended up injured and fled. Sha Fi decided to go south and waste the rest of her life in an unknown place. Meng Ke left her aunt's home and made a living by herself. The ideal of pursuing love has been repeatedly frustrated, which has tormented women's souls.

During the May 4th Movement, women were liberated from their families, which created opportunities for them to pursue independence and wander. Women portrayed by Ding Ling, through contacting friends and integrating into society, increasingly find their own interests, leave their families and go to society. In Shanghai in the Spring of 1930, Zibin and Meilin seem to be a couple of like-minded couples. When Meilin reveals that she wants to have more contact with the outside world and wants to meet and communicate regularly with friends, this incident immediately attracts Zibin's criticism. Zibin's ferocity made Meilin feel "confused and self-righteous and happy for this last long time". In Meilin's view, Zibin's spiritual oppression on her "is not like the old-style family dictatorship, which often strangles physical and mental freedom, but is another kind of deprivation of thought, action and freedom in the name of gentleness" [4]. In "Wei Hu", Lijia, who went out to study with Shanshan in Shanghai, was confused by the sweet love and was like a little puppy crouching next to Wei Hu every day. Not only did she lose herself, but she began to worry that Wei $\mathrm{Hu}$ would abandon herself and leave her whole heart to Wei Hu. When Wei Hu found that Lija had become a stumbling block to his future, he immediately left a message missing and even blamed her in the letter. At this time, Lijia realized the materialization and vulgarity of Wei $\mathrm{Hu}$, realized that she had been entrusted with a bad person, and went to revolution with her good friend Shanshan.

In Ding Ling's writings, there are also a group of women who, although not falling into the state of wandering life, are struggling between their personal desires and the heavy pressure of life and embarking on the painful journey of spiritual wandering. In "Amao Girl”, Amao, a girl from a remote mountain village, gets a chance to go to the city with her husband's support. Having experienced the prosperous and rich city, and contaminated with the rich habits of the Non-peasant class, Amao began her spiritual wandering journey from then on. When the painter from the National Academy of Art wanted Amao to be a model, her mother-in-law's face suddenly changed, and she "slapped" Amao who wanted to experience her face on the ground. At night, her husband snarled at her, Amao gradually became lifeless, tired of life, soul could not be comforted, and ideal was disillusioned. Amao realized that "happiness is only seen by others or envied or jealous, and she can never taste the sweetness". 
Yi Sa, who lives alone in the Diary of Suicide, feels that life is meaningless and has the idea of suicide. Yi Sa, lonely in Shanghai, longs for emotions, but no one gives her real emotions. Her sensitive, delicate and fragile personality often makes her despise "other people's lies, false feelings, shallow pity", but she is often be troubled by friends. Long-term mental vagrancy, she always doubts the true feelings of friends, afraid of injury and closed herself. Isn't that the quality of a vagrant?

In this ancient form of traveling, the task to be accomplished is to use reality to subvert past beliefs. Secondly, the sense of rootlessness and vagrancy generated by the collapse and breakage of culture tells us that looking for a home means that there was no home in the past [5]. The women in Ding Ling's early novels express their escape from the dull living space by wandering. They pursue the depth of life, explore the meaning of life, and subvert the power of male discourse hegemony, which leads them to wander by different routes.

\section{Typical Characteristics of Wandering Consciousness}

Women naturally need freedom, and wandering is just one way to get rid of it. Ding Ling early perceived the cost of freedom, such as illness or loneliness. She combines life experience with value standpoint, conveying vagrant sentiment and showing enterprising and seeking spiritual character. The dual traits of vagrancy lead women to drag their tired and sick bodies into a mode of "leaving home again".

Young daughters who leave home do not even have the ability to take care of themselves, so they have to face all kinds of life difficulties alone, so they are always sick and melancholy. Women in fiction often suffer from physical illness or psychological problems. Sha Fei suffers from lung disease and coughs weakly, but she rents a low, small and mildewed house for her proximity to Ling Jishi. Lung disease is often affected by mood swings. When emotions are frustrated, the illness gets worse and worse. When she lived in a hospital and felt closer to Ling Jishi, she was proud of herself. She felt that the universe was full of love, and that her illness was getting better every day. Yi Sa, a lonely girl who wants to die all the time and loses interest in everything in the world, is undoubtedly suffering from depression. The clinical symptoms of depression are persistent depression, decreased volitional activity, cognitive impairment, and even guilty delusion and hypochondriac delusion, accompanied by somatic symptoms such as sleep disorder and loss of appetite. Yi Sa's self-evaluation is too low, and there is often a sense of uselessness, helplessness and hopelessness in her heart. The room was piled with debris, scraps of paper and pear peels on the ground. She had a headache and no appetite every day. She cried until her eyelids were scraped. Most seriously, when she saw the water on the tram, it scared her. Depression, as a kind of psychological disease, can not cause death, but it makes Yi Sa unable to control his emotions and life, into a desolate and desperate situation. 
Insomnia is also a common symptom of women in Ding Ling's works. People who wander outside lose their homes are always prone to insomnia and anxiety. For the first time, Meng Ke came to her aunt's house. "She could not sleep in that sweet and soft new bed". She felt that the new environment disturbed her and restrained her. She once wrote, "I am indifferent to all glory, but unable to sleep". Insomnia in this night is due to the careful consideration of her poor life. In "Amao Girl", Amao thinks about her ideal life all day, indulges in fantasies, and often can not sleep well. "Amao is very frustrated, very hard, and on the contrary, she is excited, and can not sleep at night for a long time". After suffering from disillusionment of ideal, Amao's insomnia symptoms become more serious, "unable to sleep all night, gradually become a habit".

The loneliness of daughters is particularly prominent. They have no sense of security, are easily emotional, cry and often fall into a state of anxiety. For example, in the process of contacting with Wei Hu, Lijia often finds no sense of belonging because of Wei Hu's busy work. She is always afraid that Wei Hu will leave her, and often begins to cry without any reason. Sha Fei, who lives alone, is deeply aware of this. She plans to move to Xishan Mountain to live there. She says goodbye to all her friends and returns to her residence alone. "I pack my things lonely. I cry again at the thought of my friends who are leaving Beijing". But I wiped the tears off my face when I thought that none of my friends had ever shed tears on me. Ding Ling's description of wandering life is more true and complete because of her physical and mental illness and loneliness experience.

Leaving home is a forced wander. In order to study, earn a living or marry, this is the only way for the daughters of May 4th Movement. This kind of leaving home is often passive and compulsory, which is the beginning of women's wandering road and their lonely journey. But in Ding Ling's works, the heroines' choice of going out again deserves more attention. From the point of view that Romantics are never satisfied with reality, secularization, and never think there is an end point and destination, but are always tired of looking ahead and looking for the so-called "utopia", the wandering consciousness of Romantics is almost inevitable. Running away again after leaving home is a manifestation of their active choice to get rid of the predicament, reflecting their daughters' courage to rebel against the existing state and boldly try a new life.

From the beginning of the novel, Sha Fei left her family and lived alone in a rental house, enduring "Boy, open the kettle! Face water, man"! The noise was so disgusting that he quickly moved to Yunlin to find a new life and happiness. When her relationship with Ling Jishi was not smooth, she was determined to deplore Ling Jishi and realized that she shouldn't fall for this person, let alone let herself fall into a deep sorrow because of this, so she started to leave again. Not willing to stay in Beijing, Xishan is even more reluctant to go. I decided to take a ride south and waste the rest of my life in a place no one knows. So my heart ached. In the middle of the excitement, I laughed and pitied myself. Wandering in Sha Fei has become a way to pursue a new life. By moving and making new 
friends, she gets a sense of freshness.

Meng Ke went to stay at her aunt's home in Shanghai, but because she was humiliated by her second cousin's deception, she immediately decided to go out and fight by herself. Even though she realized that it was not going to light, but to the abyss of hell. But Meng Ke decided to leave again in order to pursue the true feelings and satisfying life she longed for. Lijia and Meilin also left their families and lived with their loved ones. When these daughters find that their ideals are bound by the attached love relationship, their spiritual pursuit conflicts with their lover's ideals, and then they go on the road of wandering one by one. Ding Ling created a series of images of vagrant women, their vagrant figure with the hurt of heart frustration, but also showed their resistance to fate. They live for themselves and succeed in being "up" women in the new era. They are the best practitioners of "Life is like a journey, everyone is a passer-by".

No matter how advantageous conditions and autonomous choices they have, their passive role and "other" status in society are still very strong. Their "rootless" consciousness from leaving their families has led to an inextricable mystery and an inescapable fate, whether in their existential state or in their soul world. Their efforts in the wandering process have also become a solemn Sisyphus-style effort.

\section{The Reasons of Ding Ling's Wandering Writing}

Ding Ling, who fled her hometown, could no longer feel the warmth of her hometown. For Ding Ling, the real home is only a space dwelling, where there are cruel and vulgar relatives and feudal autocratic elders. The spiritual home has been destroyed repeatedly because of the turbulence of the times. Born in 1904, Ding Ling lost her father at the age of four, wandering around with her widow mother and being bullied. Misery has sharpened her character and will, and doomed her to wander all her life. As a child, Ding Ling, who loves freedom and justice, has been hit again and again by her mother's debt collection, family scolding and even arranged marriage. Apart from being with her mother, the family has nothing to cherish. With the support of her mother, Ding Ling resolutely stepped out of her home and began to study. She made several good friends, such as Wang Jianhong and Wang Yizhi, in Changde. She had a strong interest in literature and actively participated in various social movements.

Her childhood experience doomed her to be attracted by personal liberation and social transformation. In her learning career, she was attracted by Lu Xun's pungent satirical stories against feudalism and revealing the dark side, and was inspired by the tradition of fighting spirit in the novel. This interest establishes the personality of women in Ding Ling's later novels, that is, to keep fighting and never stop. When the May 4th Movement took place, Ding Ling took part in the parade and went out with her classmates to shout slogans. In 1927, Jiang Jieshi rebelled against the revolutionary order, the Great Revolution led by the Communist Party of China failed, and many Communists died. Ding Ling's heart was extremely lonely and painful. "Many of the people I respect have died, some of 
my friends are persisting in the hardships, and some of them have wavered... I was in great mental pain! I couldn't find a friend other than a novel, so I wrote a novel" [6]. Her dissatisfaction with society and her recognition of women's identity in the turbulence of the times prompted her to pick up her pen and write. As a real soul vagabond, Ding Ling confronts her desires and emptiness, and produces reason and sadness in the torn pain.

The choice of each subject must be accompanied by the writer's personal psychological experience, and any deep psychological experience is always associated with the writer's value judgment, and the truly meaningful value judgment can only be completed on the basis of the profound experience, so fundamentally, every kind of value recognition is a writer's self-experience [7]. From "In the Dark" in 1928 and "Suicide Diary" in 1929, we can see that the wandering experience is undoubtedly Ding Ling's deepest life experience, all condensed in the female fate she created. Concealed in the novel are the fear of losing her homeland, the self-projection of Ding Ling's inner subjective consciousness and the externalization of her "rootless" consciousness. In Ding Ling's novels, whether it is Meng Ke, Sha Fei or Amao, family does not represent their fate. Only when they seek spiritual satisfaction and achieve their long-term ideal, they will have a feeling of "going home". In Ding Ling's novels, women do not have such a "home", which shows that Ding Ling regards these imaginary roles as a reflection of reality, in order to obtain the resonance of the soul and a kind of compensation.

Ding Ling's early novel wandering consciousness is obvious, and the most direct is still the shackles of the times on women. The May 4th Movement opened up a closed and conservative atmosphere in China. Democracy and science enlightened the people's wisdom. But in China's male-dominated society for thousands of years, the view of women has always been that "unless they are sometimes used and sometimes played with, women have hardly mattered for three thousand years" [8]. In the historical coordinates of thousands of years, women at that time only just stepped out of zero. Although female writers, such as Chen Hengzhe and Ling Shuhua, submerge their pen tips in the expressions of love, marriage and friendship, their themes are still traditional. Small family writing has not made women escape from the shackles, just as $\mathrm{Zi}$ Jun, who left the big family, still faces many difficulties after he entered and gave birth to a small family. The small family seems to be rebelling against the tradition of the big family and moving towards freedom of marriage and love, but in fact, due to the limitations of the times on women, choosing the small family is just entering another kind of bondage. In Ding Ling's novel Shanghai in the Spring of 1930, Zibin, as an advanced revolutionary, came home thinking only about how to occupy Meilin with goods and candy, and regarded Meilin as a child, trying to educate and control Meilin's will. He did not want Meilin to have her own interests, friends and career.

Ding Ling abandoned the female writing of the traditional and old family, not only because of her childhood experience, but also because of her sober under- 
standing of the current situation. Women's liberation advocated on paper is not optimistic in reality. Shanghai is a metropolis infested with foreign adventurers. Male-dominated society is integrated with the consumer market. Capitalist life is everywhere. After women leave home, they break away from the control of their husbands and fathers. However, they enter the commercial and cultural society and become products that can be marked and sold. Meng Ke was interviewed by a group of well-known literati in Shanghai, who appraised her appearance and criticized her figure face to face. The body is seen as a product, but the angry Meng Ke is unable to fight back. She can only endure the way of selling the body for a living. When Meng Ke was finalized as an actress, the person in charge handed her four ten-dollar bills very rudely, and told her that she had to play an insignificant role before she could get promoted. Then, Sha Fei's "watching" of Ling Jishi, from beautiful figure, bright red and delicate lips, knight-like manners and so on, "all these things that can make Sha Fei infatuated with, are shaped according to the standard of male urban life color market". As a woman's love demand, Sha Fei is actually another reflection of the male society's love demand for women, and it is a kind of "other people's words". For such a male-centered market rule, Sha Fei can treat Ling Jishi as a plaything, but she can't get the love she needs. Therefore, in addition to harvesting the contradiction between inner desire and reason, she will also lead to endless wandering destiny.

Women's wandering is not only the result of social pattern, but also an active choice. After leaving home, women enter an intermediary state. Old traditional families can not carry souls, but the new life has not yet been established. They can only be in a state of wandering and exploring. Meng Ke left her aunt's house and did not return home to accept her father's arrangement. This is precisely because she is still full of fantasy about her new life and is obsessed with the endless vitality of the prosperous city, so she accepts the loneliness and pain brought by wandering. Amao, who grew up in the countryside, once went to the city, his pure and simple mind was activated by urban culture. Afterwards, Amao repeatedly wanted to enter the city, and her family even scolded her, but failed. Amao was depressed and unintelligible, and finally chose to commit suicide to end her spiritual vagrancy. The weight of loneliness overwhelms the ignorant and ignorant Amao, who falls into the wilderness without belonging.

In the course of the change of the times, women were born in a passive state and constantly alienated by the developing civilization, which made Ding Ling feel depressed. In a depressed and boring social atmosphere, she uses many female images to prove the hopelessness of freedom. Only wandering can bring a moment of happiness. Writing helps Ding Ling to record the lonely corner of a woman's life. Even though she tends to repeat the theme gradually, the feeling of hope and despair alternating in her vagrancy still makes her full of expectations for life.

\section{Conclusion}

The flourishing of Chinese modern vagrant literature is the reflection of cultural 
changes in the process of Chinese social modernization, and the spiritual expression of modern writers who dare to bear the fate of vagrancy for the sake of human progress, brightness and justice. Wandering is not only a career, but also a value symbol of women's self-awareness. This kind of symbol is the symbol that writers take the existential state of women as the starting point, break away from the shackles of the "other" discourse, and reach the awakening of "human" and the awakening of women's consciousness on the other side. While thinking about women's situation, the writer also undertakes to think about women's future and destiny so as to better grasp women's vitality and endurance from the aspect of integration into society. Wandering has even become a weapon in Ding Ling's works. Only in the state of wandering can women better grasp the social dynamics, contact various groups of people and expose social ills. Standing on the stage of the times, they dance in wandering.

\section{Conflicts of Interest}

The author declares no conflicts of interest regarding the publication of this paper.

\section{References}

[1] Wang, W.P. and $\mathrm{Xu}$, L.P. (2010) The Predicament Intellectuals and Instability Soul-The New Literary Intellectuals in the Wandering Stray. Journal of Northeast Normal University, No. 1, 6.

[2] Zhang, L.L. (2008) Reflections of Love View in Literary Works on Cultural Differences between China and the West. Journal of Heilongjiang Institute of Education, No. 2,1 .

[3] Zhang, J. (2001) Complete Works of Ding Ling 3. Hebei People's Publishing House, Shijiazhuang, 43.

[4] Chang, B. (2007) Evolution of Chinese Female Literature Discourse: 1898-1949. People's Publishing House, Beijing, 222.

[5] Cao, W.X. (2002) On the "Wandering Complex" in Literature in the Past Twenty Years. Literary Review, No. 4, 5.

[6] Yang, S.S. (1998) History of the Psychology of Chinese Writers in the Twentieth Century. Central Compilation and Publishing House, Beijing, 54.

[7] Wu, Y.Q. (1993) The Soul of a Vagrant City-On XuXu. Suzhou University Press, Suzhou, 8.

[8] Chen, D.Y. (2015) The Life History of Chinese Women in the Series of Modern Chinese Academic Books. Business Press, Beijing, 1. 